\title{
Spontaneous recovery: A (Hullian) non-inhibition interpretation
}

\author{
KENNETH R. BURSTEIN \\ SIMON FRASER UNIVERSITY
}

A non-inhibition interpretation of spontaneous recovery is offered which is consistent with the main body of Hullian theory. Specifically, it is suggested that the first CS presentation in an acquisition procedure has certain characteristics which result in the maintenance of greater habit strength to it, following extinction, than to other CS presentations, and that presentation of a CS on a test of spontaneous recovery, because it involves a CS more similar to the first acquisition CS than to later nonreinforced CSs, results in an apparent recovery of response strength, since there is less generalized extinction to this CS.

Hull (1952) theorized that increments in habit strength, $\mathrm{S}^{\mathrm{H}} \mathrm{R}$, are a function of the number of reinforcements, $N$, but did not adopt the most obvious strategy with respect to extinction, i.e., nonreinforced trials result in decrements in $\mathrm{SH}_{R}$, perhaps, among other things, because this solution immediately generated another problem: How do you account for the increase in response strength which occurs, without reinforcement, after a post-extinction rest (spontaneous recovery)? Instead, Hull ingeniously elaborated upon the Pavlovian concept of inhibition to account for both extinction and spontaneous recovery.

While the robustness, and, therefore, the acceptance, of a theory of extinction is, to some extent, dependent upon the ease with which it handles spontaneous recovery, Hull's inhibition explanation, although successful in meeting this particular criterion, has not been enthusiastically accepted. In spite of a large number of experimental findings which support an inhibition interpretation of extinction-many of them not easily predicted-current appraisal of inhibition theory ranges from Kimble's $(1961$, p. 292) "inhibition of the sort postulated by the early proponents of inhibition, and by Hull, probably contributes to extinction, but cannot serve as a complete explanation" to Deese's (1958, p. 50) "it [inhibition theory] has been thoroughly demolished by critics." These evaluations are based, for the most part, on formal inadequacies in the theory (q.v., Koch, 1954), on the contradictory predictions which the theory generates (q.v., Gleitman, Nachmias, \& Neisser, 1954), and on experimental evidence which is inconsistent with an inhibition explanation (e.g., Deese, 1951; Hurwitz, 1955; Moltz, 1955).

In the face of these criticisms of the present Hullian treatment of extinction, it would seem that alternative hypotheses with respect to extinction which are not inconsistent with the main body of Hullian theory are needed. Since a part of the attractiveness of the Hullian conception of inhibition is the ease with which it deals with the phenomenon of spontaneous recovery, it seems possible that an alternative explanation of spontaneous recovery might allow contemporary theorists to explore other theoretical avenues with respect to the phenomenon of extinction. This paper attempts to present such an alternative interpretation.

Extinction denotes a weakening, typically progressive, of response strength to repeated nonreinforced presentations of the CS. In reality, however, what is generally referred to as "the CS" consists of a series of presentations of different CSs, i.e., each member of a CS series possesses some degree of uniqueness in that each is presented at a different point in time and each has a different temporal relationship to the total pattern of CS presentations. These "individualistic" aspects of conditioned stimuli can be denoted by labelling each CS with a subscript:

$$
\mathrm{CS}_{1}, \mathrm{CS}_{2}, \mathrm{CS}_{3}, \ldots \mathrm{CS}_{\mathrm{n}} \text {. }
$$

It is hypothesized that each of these "different" CSs generates a stimulus trace and that it is to these traces that habit strength is accrued. It is also assumed that the habit strength to each trace generalizes to other CS traces as a function of their similarity. Thus, if there are 30 acquisition trials followed by 10 extinction trials, only responses to $\mathrm{CS}_{31}-\mathrm{CS}_{40}$ are extinguished; ${ }^{1}$ however, through the generalization of extinction, the tendency not to respond generalizes to the stimulus traces of other CSs.

Before turning to the problem of spontaneous recovery, an examination of the degree of similarity between the individual CSs in an acquisition-extinction procedure may have some heuristic value. Thus, it should be noted that $\mathrm{CS}_{1}$ is quite dissimilar from the other CSs within an acquisition-extinction procedure in that it is the only CS which is not preceded by a CS presentation. $\mathrm{CS}_{1}$ is also different from other $\mathrm{CS}$ presentations in that its occurrence follows events quite dissimilar from those preceding other CS presentations, i.e., intersession events are typically quite dissimilar from intertrial events, both with respect to the kinds of stimulation involved and with respect to their frequency of occurrence.

Because of this dissimilarity, the tendency not to respond acquired during an extinction procedure generalizes much less to the trace of $\mathrm{CS}_{1}$ than it does to other CS traces. Since the operations for obtaining 
spontaneous recovery involve, by definition, a fairly lengthy period prior to the test for spontaneous recovery, the CS presentation by which spontaneous recovery is tested is much more similar to $\mathrm{CS}_{1}$ than to other previous CS presentations, in that it is not directly preceded by another CS. For this reason, response strength is much greater to this test stimulus than it was to the previous CS presentation, 1.e., to the CS on the last extinction trial.

A study by Liberman (1944) offers strong support for the position taken here with respect to the role of generalization in extinction and in spontaneous recovery. Liberman found that interpolating eyelid conditioning trials during the period between the extinction and test of recovery of a conditioned GSR increased the amount of spontaneous recovery of the GSR. He also found that if the stimuli for the original and the interpolated conditioning were similar (1000 cps tone and buzzer), the effects upon spontaneous recovery were greater than if the stimuli were dissimilar (1000 cps tone and light).

Repeated extinction sessions with intervening rest periods and "below zero" extinction procedures would, according to the view taken here, result in more generalized extinction to $\mathrm{CS}_{1}$ and, therefore, in less spontaneous recovery. In the former instance, the initial CS presentation on each repeated extinction session would, because of the intervening rest, resemble $\mathrm{CS}_{1}$, and the repeated extinction of the response to such a stimulus would result in more and more generalized extinction. In the latter case, long serles of extinction trials after the cessation of responses would result in greater summation of the generalized tendency to not respond. Osgood (1953, p. 337-338) reports that these two procecures do result in less spontaneous recovery than is obtained in control groups, a finding which supports the point of view taken here.

It should be noted that the view expressed in this paper 18, in some ways, similar to one suggested by Skinner (1950): "the stimulation coincident with the beginning of an experiment must be extensive and unlike anything occurring in the later part of an experimental period... When the organism is again placed in the experimental situation, the stimulation is restored;" (p. 55). Skinner, however, seems to emphasize stimulation extraneous to the conditioning procedure itself, e.g., handling the $S$, placing $S$ in the experimental situation, etc., while the view taken here emphasizes events within the conditioning procedure. It seems quite possible, if not likely, that Skinner's extraneous events also play a role in spon- taneous recovery. Also, along these lines, the simllarity of the intersession waiting period to the pre-spontaneous recovery wait period may be an important factor in spontaneous recovery.

The position of Estes (e.g., 1959, p. 462) with respect to spontaneous recovery may also be interpreted as similar to the one presented here. Thus, one could view differences in sequentially presented CSs as corresponding to Estes' different stimulus elements and could also regard the CS presented on a test for spontaneous recovery as being less extinguished than those CSs presented during extinction because of a greater resemblance to the originally conditioned stimulus elements than to the extinguished stimulus elements. However, it is recognized that the CS presented on the recovery trial is not, strictly speaking, a residual stimulus element, and that viewing it as such might be objectionable to some adherents of the statistical sampling theory of learning.

\section{References}

Deese, J. The extinction of a discrimination without performance of the choice response. J. comp. physiol. Psychol., 1951,44, 362-366.

Deese, J. The psychology of learning, (2nd ed.) New York: McGrawHill, 1958.

Gleitman, H., Nachmias, J., \& Neisser, U. The S-R reinforcement theory of extinction. Psychol. Rev., 1954, 61, 23-33.

Hull, C. L. A behavior system. New Haven: Yale University Press, 1952.

Hurwitz, H. M. B. Response elimination without performance. Quart. J. exp. Psychol., 1955, 7, 1-7.

Kimble, G. A. Hilgard and Marquis' conditioning and learning. New York: Appleton-Century-Crofts, 1961.

Koch, S. Clark L. Hull. In Estes, et al. Modern learning theory. New York: Appleton-Century-Crofts, 1954.

Liberman, A. M. The effect of interpolated activity on spontaneous recovery from experimental extinction. J. exp. Psychol., 1944, 34, 282-301.

Moltz, H. Latent extinction and reduction of secondary reward value. J. exp. Psychol., 1955, 49, 395-400.

osgood, C. E. Method and theory in experimental psychology. New York: Oxford University Press, 1953.

Skinner, B. F. Are theories of learning necessary? Psychol. Rev., $1950,57,193-216$. In B. F. Skinner, Cumulative record. New York: Appleton-Century-Crofts, 1961.

Spence, K. W. Behavior theory and conditioning. New Haven: Yale University Press, 1956.

Estes, W. K. The statistical approach to learning theory. In S. Koch, Psychology: A study of a science, New York: McGrawHill, 1959.

\section{Noie}

1. It matters not, for this argument, what the nature of the mechanism or process underlying extinction is, i.e., whether non-reinforced trials result in decrements in habit strength, or in the conditioning of motor and/or emotional responses which are incompatible with the CR undergoing extinction, or in increasing the effect of some (primarily descriptive) inhibitory variable, e.g., Spence's (1956) $I_{n}$. 